\title{
THE OPERATING BEHAVIOUR OF UNBALANCED, UNPACED MERGING ASSEMBLY LINES
}

\author{
Tom McNamara ${ }^{1}$, Sabry ShaAban ${ }^{2}$ Abdelkader Sbihi ${ }^{3, *}$ And Zouhair LaArraF ${ }^{4}$
}

\begin{abstract}
Unbalanced assembly line research has grown in importance because of its increasing applications in emerging economies, reverse logistics and remanufacturing. This paper examines the performance of numerous simulated patterns for reliable unbalanced manual merging assembly lines. The contribution of this study to the literature is that imbalance does not always negatively impact efficiency and that it can improve merging line performance when compared to a corresponding balanced merging line. The best performance was found to be a balanced line configuration and a monotone decreasing order for both parallel merging lines, with the former generally resulting in a lower throughput and the latter resulting in a lower average buffer level than that of a balanced line.
\end{abstract}

Mathematics Subject Classification. 90B30, 90B70.

Received October 21, 2019. Accepted November 2, 2020.

\section{INTRODUCTION}

Production lines have existed since the introduction of craft systems in the pre-industrial world and yet they continue to develop and evolve even in today's advanced manufacturing methods [12].

Unpaced merging lines are probabilistic queuing systems in series. With no form of mechanical pacing, operators along the line can work at their own pace. Inventories of work-in-process (WIP) are stored in buffers between stations. A typical merging assembly line with parallel work stations, buffers and a final merge or assembly station is shown in Figure 1.

Non-automated unpaced assembly lines are widespread in less developed economies, remanufacturing and reverse logistics. Given the trend towards outsourcing of production to developing countries, this study has global implications. Additionally, especially in remanufacturing and reverse logistics, demand and supply are different from those typically found in classical manufacturing [15, 20].

Remanufacturing supply, in contrast to traditional manufacturing, does not usually provide reliable volumes of standard and uniform quality products. Unlike in traditional manufacturing's long-term planning, these assembly lines may be set up for minimal time periods to seize upon short-term demand bursts, and then

Keywords. Merging lines, imbalance patterns, average buffer level, throughput, simulation.

1 Department of Supply Chain Management, Rennes School of Business, 2 Rue Robert d'Arbrissel, 35065 Rennes, France.

2 Department of Strategy, La Rochelle School of Business, 102 Rue de Coureilles, 17024 La Rochelle, France.

3 Department of Finance, Operations and Marketing, Brest Business School, 2 Avenue de Provence, 29200 Brest, France.

4 Department of Human Resources and Management, La Rochelle School of Business, 102 Rue de Coureilles, 17024 La Rochelle, France.

* Corresponding author: abdelkader.sbihi@brest-bs.com, abdelkader.sbihi@univ-paris1.fr 


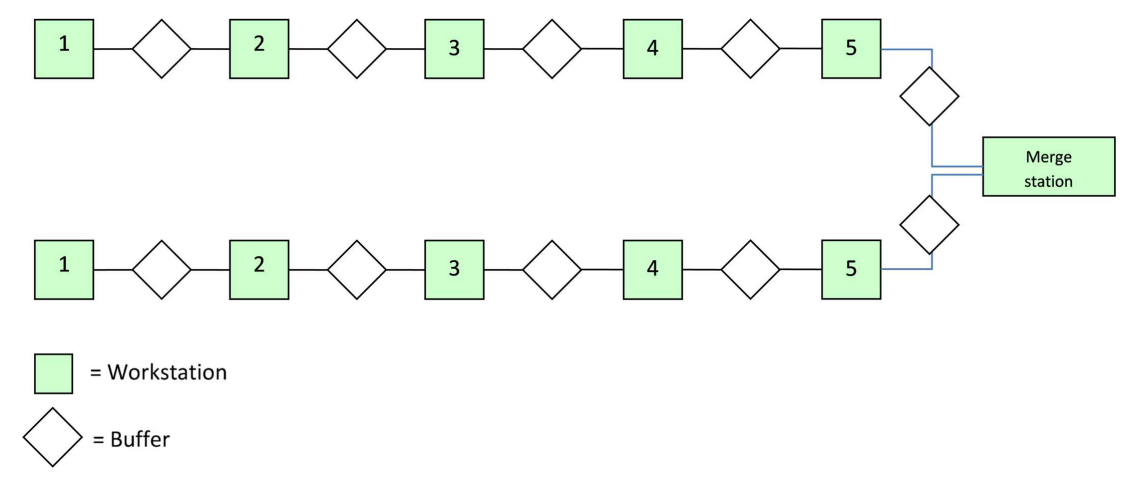

Figure 1. An assembly line with five parallel stations, buffers and a merge station.

disassembled, thus augmenting process variability [27]. The explosive growth in remanufacturing and reverse logistics, underlines the global importance of research on unbalanced, unpaced assembly lines are reinforced, which emphasizes the contribution of this work.

In unpaced lines, there is a greater likelihood of differing worker speeds since station operators can vary their speeds depending on their physical capacity, motivation level, task complexity, or an uneven distribution of work along the line. Differences in mean operation times (MTs) lead to blocking and starving along the line with impacts on average buffer level (ABL) and throughput (TR) [55]. Consequently, the allocation of operators along the line needs to be taken into account in order to achieve improved performance.

Simulation has been used extensively to evaluate various assembly line configurations $[10,26,44]$. In the configurations studied here, results suggest that imbalance does not necessarily lead to deterioration in performance, and in many cases can enhance efficiency in merge lines when compared to a corresponding balanced merging line. This raises questions about the ideal of a notionally balanced line providing exemplary performance and contributes to the current literature on unbalanced lines.

One can also notice that discrete-event simulation is an effective modeling tool that can be applied to an exploratory research setting to deal with stochastic systems. It allows the researcher to conduct a variety of experiments by manipulating the system's parameters to study the effect of certain variables on the system, and is well-suited to the setting [59].

The remaining structure of the article is as follows. First we provide a brief literature. Then we present research motivation and study objectives. Subsequent sections discuss the methodology and design of experiments and provide simulation results and analysis. The outcomes are summarised and discussed in the last two sections, with future research directions suggested.

\section{Literature REVIEW}

Early research on unbalanced mean times suggested that if stations with higher average working times were placed at both ends of a single serial line could result in higher throughput (TR) than that of a balanced line. This was termed the "bowl phenomenon" by Hillier and Boling [25]. Since then, the phenomenon has been repeatedly retested, and results have been mixed. More recent studies have concentrated on patterns of imbalance rather than solely on the bowl phenomenon [11,24,27,32,41,45, 55].

In an early simulation comparison study between a system of two parallel serial lines versus another with an equal number of stages, where each stage has two stations that merge, Moberly and Wyman [46] found that both systems were unreliable with normally distributed work times and that the performance of the merging stations system was better than that of a parallel serial line. 
Maani and Hogg [42] developed a simulation model to assess the performance of merging lines with stochastic processing times, in order to balance them. Liu and Buzacott [40] proposed a method to predict the performance of unreliable assembly merging line systems with unequal cycle times, using an assembly stage fed by two or more stages. Building on this, Baker et al. [4] studied merging assembly systems and found that - pull - systems had lower average output than - push - mode.

In a latter study, Baker et al. [5] investigated a three-station merging system composed of two feeders and one assembly station. Interestingly, they found that an unbalanced configuration was optimal, and that TR remained stable if the assembly station work allocation ranges from 0.42 from 1 . Their simulations of longer two-station feeder lines showed lower overall TR enhancement and better TR results from unbalanced systems than from a balanced counterpart system.

Bhatnagar and Chandra [6] also employed simulation to investigate assembly systems with three stations. They obtained higher improvements in TR from increasing the production rate (decreasing the operation times) of individual stations than those from increasing buffer capacities (BCs).

Baker and Powell [3] went on to present an efficient approximation method for generating the output of a simple assembly system with three stations and random unequal service times. Several years later, Powell and Pyke [49] took this research stream further by offering general guidelines for the effective allocation of buffers in unbalanced assembly systems with random service times.

Magazine and Stecke [43] suggested that unbalanced feeder stations in a merging line can perform as good as, or even better than, a balanced system. The objective of their study was to determine how best to allocate service capacity in lines with 2 or 3 workstations, split into parallel servers, to maximize TR. Several conclusions from this study are worth highlighting. First, for fixed resources they stated that the - symmetrical allocation' property holds, i.e. allocating more servers to the middle station and having equal numbers of parallel servers on stations 1 and 3. To keep TR optimal in cases where imbalance becomes very severe, they recommended that a server is added to the first and third stations and one is removed from the middle station. Second, they observed that the - bowl phenomenon - holds true for any parameter set that maximizes TR. Finally, they also noted that a bowl-shaped severe imbalance is possible in such parallel operators than in a serial transfer line.

In a subsequent paper, Jeong and Kim [29] developed an approximation procedure for measuring the performance of unreliable merging assembly/disassembly lines, with exponential failure, repair and service rates. Jeong and Kim [30] went on to study buffered production systems with feeder stations merging into an assembly station. They suggested heuristics to determine the configuration which would achieve a minimal-cost TR.

Complementary work includes Futamura's investigation [17] of optimal distribution of servers to serial queueing networks with unbalanced service time means (MTs), coefficients of variation (CVs) and buffer capacities (BCs), which showed a general interaction between the number of servers at the stations and operation time distribution's CV, and that the optimal pattern is possible to predict.

Tan [58] studied an unreliable merging system with two stations in parallel and different service rates that feed into a common buffer, which in turn feeds an assembly station. He developed a decomposition approach for determining the expected buffer levels and production rate. That same year, Patchong and Willaeys [47] developed a modeling methodology for parallel flow lines in tandem. The aim was to generate equivalent parameters for sets of parallel machines. They maintained that their methodology is applicable to lines with various unreliability conditions and operation times for diagnosis of TR or average buffer level performance.

Research in this field progressed with a study by Rekhi et al. [51] into unbuffered stochastic production systems where an assembly station was fed directly by multiple component stations. They used simulation to study systems comprised of up to 40 component stations. Results indicated that an increase in the number of component stations in a system would lead to an increase in the TR of that system.

Sabuncuoglu et al. [53] used simulation to study the effects of design factors (such as number of stations, processing times and variability) on TR and variability of inter-departure times in assembly systems. They generated improved guidelines for more efficient production systems design. 
Leung and Lai [38] developed a plan for the installation of parallel stations to improve cycle times as compared to simple assembly systems. They found that off-line parallel systems were most effective to decrease buffer requirements and sensitivity to MT and CV imbalances, compared to tunnel-gated and on-line systems.

In a work by Gökçen et al. [18], the authors maintained that balancing merging lines produces superior performance. Abu Qudeiri et al. [1] presented an algorithm to find the optimal design for serial parallel assembly lines with unequal BCs and with workstations that had different machine numbers and types. By applying their algorithm to a parallel line system with five machines in each line, they found that this led to an increase in production efficiency from $80 \%$ to $85 \%$.

Grosfeld-Nir and Ben-Zvi [19] developed heuristics to analyse several systems, including merging lines, with respect to costs under tight demand conditions. Control limits were set to assure processed lots at stations are not too small (resulting in high costs), or too large (leading to undesirable surplus). They concluded that by solving a finite set of linear equations, expected costs can be computed for any multistage system.

Complementing that work, Jia et al. [31] investigated the transient behavior of assembly systems with unreliable merging lines in series, Bernoulli machines, and finite BCs. They derived formulas to measure TR, WIP, as well as individual station blocking and starving probabilities. This resulted in the development of an analytical procedure to bigger and complex assembly systems with assembly/merge stations and multiple feeder lines).

Using simulation and genetic algorithm, Tiacci [60] examined a mixed-model line with parallel workstations and stochastic service times. He simultaneously studied the balancing and buffer allocation problems by varying individual stations' work assignments and buffer capacities. His results indicated that buffer usage can improve TR even when a unit buffer space cost was considered.

Recently, Yegul et al. [63] studied a real complex manufacturing system using a simulation-optimisation approach. Their research focused on maximising the manufacturing system's profit by optimising the mean speed (MT), number of parallel machines, buffer sizes, and allocation of workers to some stations, while taking into account stochastic setup, processing, durations of mean-time-to-failure \& mean-time-to-repair, and costs of labour, machine investments and inventory holding. They suggested that the most important elements in the system's profit function are the numbers of machines and workers in a subset of stations.

In the paper by Shaaban et al. [56], the authos studied the performance of unpaced reliable merging lines with varying line lengths, mean buffer capacities and uneven buffer allocation configurations. They found that higher TR and lower ABL, as compared to a balanced merging line counterpart, were respectively achieved with as even allocation of total available buffer capacity as possible, and with a higher buffer capacity concentration towards the end of the line.

More recently, Romero-Silva and Shaaban [52] simulated unpaced, unreliable merging lines, with various buffer sizes, number of stations, degrees of imbalance and patterns of unbalanced MT and BC allocations. For MT imbalance, it was reported that higher values of TR were achieved from an inverted bowl shape, or a descending order, as compared to a balanced merging line counterpart. With respect to ABL, the best pattern turned out to be a monotone decreasing order regarding MT and a monotone increasing arrangement for BC allocation. Furthermore, when considering a profit function for unreliable lines, it was indicated that the best performing patterns are identical to those pertaining to ABL above, even for very low inventory carrying costs.

Many industries contain assembly lines that include the components under study here, and the apparel industry is an exemplar. Much clothing manufacturing occurs in less developed countries for export, is labour intensive and manual, and results in stochastic (variable) line behavior [14,21]. Theoretically, if each garment is worked on in a predetermined order, with no two operators processing the same work piece at the same time, no balancing problems should arise [8]. But in actual practice, this is rarely the case.

Much of the literature dealing with apparel assembly lines uses simulation and analytical mathematical investigations to improve performance. Common complexity issues addressed via simulation and analytical studies include various levels of automation versus line balance/ imbalance, manual work, machine reliability, material starving, line configurations (e.g. push, Kanban, modular), scheduling, and work station placement.

Apparel specific simulation studies on assembly lines have been undertaken over the previous decades and include initial works by Cocks and Harlock [9] and Fozzard et al. [16]. These works were extended by Zielinski 
and Czacherska [64], Kalaoğlu and Saricam [33] and Güner and Ünal [22], while more recent simulation-based work has included research by Bahadir [2], Rahman et al. [50] and Kayar and Akalin [34,35].

As shown, merging assembly line research continues to advance, although it has historically done so mostly with a focus on the development of mathematical models. This study uses simulation and statistical analysis to investigate if unbalancing parallel workstations' MTs could yield better results than the use of a fixed line MT rate. It also examines if various parallel workstation MT patterns impact performance and how imbalance degree, pattern of MT imbalance, buffer capacity, and line length affect merging line performance. Results will apply across many industries, and to help illuminate application, we focus on lines in the apparel industry, which provides a common context for imbalanced, unpaced, and merging assembly lines.

It is hoped that this research contributes a novel perspective and contrasts with previous research using predominantly mathematically modelled assembly line behaviour.

\section{Motivation AND OBJECTIVES}

The contribution of this study, which is applicable to developing economies, remanufacturing and reverse logistics, is two-fold.

First, substantial capital and other resources are invested on merging assembly lines' design, installation, operation, and maintenance. Even slight inventory cost reductions or efficiency enhancement can lead to big savings over the lifespan of a line.

Second, achieving a balanced MT merging line is unrealistic, particularly in the global context of outsourcing to countries with low labour costs. According to the World Trade Organization (WTO), India is the third largest clothing exporter (WTO, 2014) accounting for $\$ 16.8 \mathrm{~B}$ (US) of trade and experiencing $23 \%$ market growth from 2012 to 2013. Turkey, Bangladesh, and Vietnam follow closely as apparel exporters. Continued industry growth in these markets provides large-scale employment opportunities and also opportunities to generate increased production line performance. Cheap, perhaps untrained workers recruited on an ad-hoc project basis, may not have the motivation or expertise for consistent performance. Increasing the theoretical and practical understanding of best practices for variable unbalanced merging assembly lines can lead to enhanced productivity and resource utilization and decreased waste.

Since most assembly lines experience some degree of imbalance in real-life, examining the potential benefits and consequences of deliberately unbalancing a line should generate substantial managerial discussion.

The focus of this paper is on merging assembly lines having a single imbalance source, whereby the MTs differ amongst workstations, whereas the BCs and CVs along the line are held equal. Additionally, systems of 5and 8-station lines with three degrees of MT imbalance (the difference in MT between adjacent stations) were simulated.

The merging assembly line in this study is representative of a generic apparel manufacturing system, similar in configuration to those discussed by Kuo et al. [36] and Li et al. [39]. As a result of a research paucity on unbalanced, unpaced merging assembly lines, this article contributes to the literature via a systematic and comprehensive study that hopefully attempts to close some of the gaps left by the particular methodologies of previous research. The research objectives are:

(1) Test the impact of MT imbalance pattern on the performance of the merging line studied compared to that of a merging balanced line counterpart.

(2) Find the configurations generating the best performance.

(3) Determine the relative effects of line length, BC, MT imbalance pattern, MT degree of imbalance on performance.

To the most of our knowledge, there exist no previous studies that have explicitly addressed these issues by the past. 


\section{Methodology AND EXPERIMENTAL DeSign}

Given the methodological limitations of mathematical modelling in representing real-life, more complex tandem merging lines, typically reported with right-shifted service times, computer simulation was regarded as the most useful tool for this research. ProModel Version 7.5 coded manufacturing simulation model was utilised to study the unbalanced merging line performance.

\subsection{Factorial design, performance indicators and statistical methods}

A complete factorial design was employed. The independent variables used for the particular merging line studied were:

- Buffer capacity, BC.

- Degree of imbalance, DI - the percentage difference in MT between successive stations.

- Number of stations (line length), $N$.

- MT imbalance pattern, MTP (for parallel lines 1 and 2).

A positively skewed Weibull distribution was used to simulate more realistic operation times, in line with [57] contention that this probability distribution closely depicts real-life unpaced operation times.

Two performance indicators were used; line throughput (TR) and line average buffer level (ABL). The study goal is to determine the specific configurations which augment TR and/or reduce ABL.

To analyse TR and ABL data, the following statistical methods were utilised:

- Multiple comparisons with control (the equivalent MT balanced line) using the Dunnett's $t$-test.

- Multiple pairwise comparisons to compare the performance of MT patterns using Tukey's HSD test.

- Generalized Linear Model (GLM) to determine the relative contributions of the independent variables to the dependent variable performance.

SPSS V20 was used to carry out the above statistical analyses.

\subsection{Simulation run parameters and model assumptions}

Minimum autocorrelation values of -0.20 to +0.20 should be obtained to assure independent observations (for more details, the reader may refer to [23,37]). A trial simulation experiment has confirmed that acceptable autocorrelation values of -0.163 to +0.153 were generated after a 20000 min warm up period, indicating that adjacent blocks were relatively independent. This initial run was increased to $30000 \mathrm{~min}$ to ensure more valid statistical data. Data gathered during the initial 30000 min were thrown away and a 20000 min production run, divided into 50 sub-runs or blocks of $400 \mathrm{~min}$ each was then collected (i.e. mean TR's and ABLs were computed every $400 \mathrm{~min}$ ), and the average (grand) mean of these 50 mean values was determined. In addition, an identical random seed number was used in all simulation runs to generate the same sequence of events for all configurations and highlight any contrasts amongst them.

The standard line type assumptions made are:

- The line produces only one type of product, with no defective items.

- The first station is never starved of work and the last station is never blocked.

- Time to move a work unit in and out of the buffers is tiny, hence ignored.

The operating conditions described above represent agreement with previous simulation studies $[13,48,54]$.

\subsection{Merging line features}

For parallel lines 1 and 2, the line lengths $(N \mathrm{~s})$ experimented with were $N=5$ and $N=8$ (both odd and even numbers). Additionally, the total buffer capacity was distributed evenly along the line and set at $\mathrm{BC}=$ 1,2 and 4 units. Furthermore, each station's CV was fixed at 0.274 , corresponding to [57] determination that this represents the average value found in actual manual unpaced production lines. The mean operation time 
TABLE 1. Basic merging line design features.

\begin{tabular}{|c|c|c|c|c|c|}
\hline $\begin{array}{l}\text { Performance } \\
\text { Indicator }\end{array}$ & $\begin{array}{c}\text { Line } \\
\text { Length (N) }\end{array}$ & $\begin{array}{c}\text { Buffer } \\
\text { Capacity } \\
\text { (BC) }\end{array}$ & $\begin{array}{c}\text { \% Degree of } \\
\text { Imbalance in } \\
\text { Operation } \\
\text { Times (DI) }\end{array}$ & $\begin{array}{l}\text { MT Pattern } \\
\text { (Line 1) }\end{array}$ & $\begin{array}{c}\text { MT } \\
\text { Pattern } \\
\text { (Parallel } \\
\text { Line 2) } \\
\end{array}$ \\
\hline $\begin{array}{l}\text { Average Buffer } \\
\text { Level (ABL) }\end{array}$ & \multirow{2}{*}{$\begin{array}{l}\text { 5-station line } \\
8 \text {-station line }\end{array}$} & \multirow{2}{*}{$1,2,4$ units } & \multirow{2}{*}{$2,5,12$} & $\begin{array}{l}(\) \\
(/) \\
(\Lambda)\end{array}$ & $\begin{array}{l}(\backslash) \\
(/) \\
(\Lambda)\end{array}$ \\
\hline Throughput (TR) & & & & $\begin{array}{c}(\mathrm{V}) \\
(--) \\
\text { (balanced) }\end{array}$ & $\begin{array}{c}(\mathrm{V}) \\
(--) \\
\text { (balanced) }\end{array}$ \\
\hline
\end{tabular}

(MT) base case was fixed at $10 \mathrm{~min}$ and the degree of MT imbalance (DI) was set at $2 \%, 5 \%$ and $12 \%$, with $2 \%$ indicating a slight imbalance level and $12 \%$ reflecting a relatively high imbalance degree. For example, in the case of $N=5, \mathrm{DI}=5 \%$, and a monotone increasing order (/), the MTs at the five stations would be: station 1 (9.025 min); station 2 (9.500); station 3(10.000); station 4(10.500); and station 5 (10.975 min). According to Vonderembse and White [61], even well-balanced lines have idle times in the order of $2 \%$. Hutchinson et al. [28] indicated that a DI of $5 \%$ was considered acceptable. To gauge the impact of a relatively large DI on a merging assembly line, an additional value of $12 \%$ was used. The MT values employed are similar to those used by Blackstone Jr and Cox III [7].

For both parallel lines 1 and 2, five different MT imbalance patterns were considered:

- A balanced line configuration (-).

- A monotone decreasing order $(\backslash)$ - from slowest to fastest workers.

- A monotone increasing order $(/)$ - from fastest to slowest workers.

- An inverted bowl arrangement $(\Lambda)$ - positioning the slowest workers in the middle.

- A bowl arrangement (V) - positioning the fastest workers in the middle.

Table 1 summarises the merging line features.

Overall, a total of 432 simulation runs were carried out as follows:

$[2 N$ levels $\times 3$ BC levels $\times 3$ DI levels $\times 24 \mathrm{MT}$ imbalance configurations $=432$ cells +6 balanced line $(--$, $--)=438$ runs].

\section{Simulation RESUlts And DATA ANALYSis}

Tables $2-5$ present the grand mean values of TR and ABL. Note that higher TR and lower ABL values in comparison with their corresponding balanced control line $(--,--)$ values, are lightly shaded, indicating positive performance.

In addition, those values differing significantly from the balanced line data are noted with asterisks. Combined better performance and significance are heavily shaded.

Objective 1: Test the impact of MT imbalance pattern on the performance of the merging line studied compared to that of a merging balanced line counterpart.

To determine the influence of MT imbalance configurations on performance, multiple comparisons with control utilizing the Dunnett's $t$-test were done on TR and ABL data at all considered levels of $N, \mathrm{BC}$ and DI, comparing them to corresponding balanced line values.

Tables 2 and 3 indicate that in terms of TR, a balanced line is generally superior, even though a few unbalanced patterns (especially at DI $=2 \%$ and $N=5$ ) insignificantly outperformed the balanced configuration. Also, it 
TABLE 2. TR results for a merged line with $N=5$ parallel stations, $\mathrm{BC}=1,2$ and 4 units, $\mathrm{DI} \%=2,5$ and 12 , and a balanced line, ${ }^{*} p<0.05,{ }^{* *} p<0.01,{ }^{* * *} p<0.001$.

\begin{tabular}{|c|c|c|c|c|c|c|c|c|c|}
\hline \multirow{3}{*}{$\begin{array}{l}\text { MT } \\
\text { Pattern } \\
\text { Line 1, 2 }\end{array}$} & \multicolumn{9}{|c|}{ Line length $(\mathrm{N})=5$} \\
\hline & \multicolumn{3}{|c|}{ Buffer Capacity $(B C)=1$} & \multicolumn{3}{|c|}{$\mathrm{BC}=\mathbf{2}$} & \multicolumn{3}{|c|}{$\mathrm{BC}=4$} \\
\hline & $\mathrm{DI}=\mathbf{2}$ & $\mathrm{DI}=5$ & $\mathrm{DI}=12$ & $\mathrm{DI}=2$ & $\mathrm{DI}=5$ & $\mathrm{DI}=12$ & $\mathrm{DI}=\mathbf{2}$ & $\mathrm{DI}=5$ & $\mathrm{DI}=12$ \\
\hline,-- 1 & 0.895 & 0.893 & $0.853^{* * *}$ & 0.934 & 0.928 & $0.873 * * *$ & 0.964 & $0.939 *$ & $0.877^{* * *}$ \\
\hline,$-- /$ & 0.895 & 0.887 & $0.849 * * *$ & 0.934 & 0.923 & $0.869 * * *$ & 0.960 & $0.939 *$ & $0.877^{* * *}$ \\
\hline,$-- \Lambda$ & 0.900 & 0.899 & 0.899 & 0.943 & 0.938 & 0.928 & 0.969 & 0.962 & $0.927^{* * *}$ \\
\hline,$-- \mathrm{V}$ & 0.898 & 0.896 & 0.888 & 0.936 & 0.931 & 0.917 & 0.963 & 0.956 & $0.927 * * *$ \\
\hline$\backslash,--$ & 0.898 & 0.898 & $0.855^{* * *}$ & 0.939 & 0.921 & $0.869 * * *$ & 0.962 & $0.950^{*}$ & $0.886^{* * * *}$ \\
\hline 1,1 & 0.901 & 0.894 & $0.845^{* * *}$ & 0.940 & 0.930 & $0.865^{* * *}$ & 0.961 & 0.944 & $0.880^{* * *}$ \\
\hline 1,1 & 0.901 & \begin{tabular}{|l|}
0.887 \\
\end{tabular} & $0.845^{* * *}$ & 0.935 & 0.922 & $0.863^{* * * *}$ & 0.964 & $0.939^{*}$ & $0.882^{* * * *}$ \\
\hline$\downarrow, \Lambda$ & 0.905 & 0.897 & $0.854^{* * *}$ & 0.939 & 0.925 & $0.874 * * *$ & 0.965 & $0.943 *$ & $0.870^{* * *}$ \\
\hline $1, \mathrm{~V}$ & 0.894 & 0.889 & $0.858^{* * *}$ & 0.934 & 0.923 & $0.881^{* * *}$ & 0.961 & $0.939^{*}$ & $0.881^{* * *}$ \\
\hline I,-- & 0.897 & 0.887 & $0.860^{* * *}$ & 0.938 & 0.918 & $0.866^{* * * *}$ & 0.963 & $0.937 *$ & $0.877^{* * *}$ \\
\hline 1,1 & 0.898 & 0.889 & $0.848^{* * * *}$ & 0.937 & 0.921 & $0.866^{* * *}$ & 0.956 & $0.939 *$ & $0.867 * * *$ \\
\hline 1,1 & 0.894 & $0.883 *$ & $0.832 * * *$ & 0.934 & $0.915^{*}$ & $0.855^{* * *}$ & 0.961 & $0.933^{* *}$ & $0.872^{* * *}$ \\
\hline I, $\Lambda$ & 0.898 & 0.885 & $0.851^{* * *}$ & 0.933 & 0.925 & $0.870^{* * *}$ & 0.958 & 0.946 & $0.875^{* * * *}$ \\
\hline $1, \mathrm{~V}$ & 0.896 & 0.890 & $0.851^{* * *}$ & 0.928 & 0.927 & $0.869 * * *$ & 0.957 & $0.941 *$ & $0.877^{* * *}$ \\
\hline$\Lambda,--$ & 0.897 & 0.898 & 0.895 & 0.938 & 0.935 & 0.919 & 0.966 & 0.958 & $0.933^{* * *}$ \\
\hline$\Lambda, \backslash$ & 0.896 & 0.897 & $0.851^{* * *}$ & 0.938 & 0.925 & $0.872 * * *$ & 0.958 & $0.939^{*}$ & $0.876^{* * *}$ \\
\hline$\Lambda, /$ & 0.901 & 0.889 & $0.848^{* * *}$ & 0.934 & 0.924 & $0.879^{* * * *}$ & 0.959 & 0.944 & $0.889^{* * * *}$ \\
\hline$\Lambda, \Lambda$ & 0.902 & 0.896 & 0.884 & 0.938 & 0.933 & 0.926 & 0.968 & 0.958 & $0.925^{* * *}$ \\
\hline$\Lambda, \mathrm{V}$ & 0.895 & 0.897 & $0.883^{*}$ & 0.934 & 0.933 & $0.909^{* *}$ & 0.961 & 0.955 & $0.926^{* * *}$ \\
\hline $\mathrm{V},--$ & 0.898 & 0.895 & 0.884 & 0.934 & 0.929 & 0.919 & 0.969 & 0.957 & $0.930^{* * *}$ \\
\hline $\mathrm{V}, 1$ & 0.895 & 0.891 & $0.859^{* * *}$ & 0.937 & 0.926 & $0.867 * * *$ & 0.964 & $0.937^{*}$ & $0.882^{* * *}$ \\
\hline $\mathrm{V}, 1$ & 0.895 & 0.889 & $0.845^{* * *}$ & 0.933 & 0.919 & $0.867 * * *$ & 0.956 & $0.936^{*}$ & $0.882^{* * *}$ \\
\hline $\mathrm{V}, \Lambda$ & 0.898 & \begin{tabular}{|l|}
0.899 \\
\end{tabular} & $0.888^{*}$ & 0.941 & 0.935 & $0.911^{* *}$ & 0.966 & 0.958 & $0.927^{* * *}$ \\
\hline $\mathrm{V}, \mathrm{V}$ & 0.897 & 0.895 & $0.875^{* *}$ & 0.936 & 0.930 & $0.905^{* *}$ & 0.965 & 0.956 & $0.926^{* * *}$ \\
\hline $\begin{array}{c}\text { Balanced } \\
(--,--)\end{array}$ & \multicolumn{3}{|c|}{0.900} & \multicolumn{3}{|c|}{0.934} & \multicolumn{3}{|c|}{0.964} \\
\hline
\end{tabular}

can be observed that the balanced line arrangement is insignificantly superior to that of the unbalanced patterns at a low degree of MT imbalance (DI $=2 \%)$.

Tables 4 and 5 show that for ABL the descending MT order $(n, n)$ consistently outperforms the balanced line, with very highly significant improvements over the balanced line performance, especially for higher $N, \mathrm{BC}$ and DI values. In addition, other patterns with a descending order in either parallel line 1 or 2 also achieved predominantly better performance as compared to the balanced line. It was also observed that in most cases, the ascending order $(/, /)$ performs significantly worse than the control line with respect to ABL.

\section{Objective 2: Find the configurations generating the best performance.}

Multiple pairwise comparisons (Tukey's HSD) were performed to compare and rank the MT imbalance patterns across all used values of $N, \mathrm{BC}$ and $\mathrm{DI}$ to the equivalent balanced line counterpart. Table 6 summarizes these results $(p=0.000)$.

From Table 6, it is clear that the best performing MT imbalance patterns differ between TR and ABL. For $\mathrm{TR}$, the best configuration is in general a balanced line $(--,--)$. Moreover, the best MT imbalance patterns are balanced line + bowl-shaped, balanced + inverted bowl, bowl + bowl, and inverted bowl + inverted bowl MT. They perform as well as the balanced line in many cases, so whenever a balanced line configuration proves 
TABLE 3. TR results for a merged line with $N=8$ parallel stations, $\mathrm{BC}=1,2$ and 4 units, $\mathrm{DI} \%=2,5$ and 12 , and a balanced line, ${ }^{*} p<0.05,{ }^{* *} p<0.01,{ }^{* * *} p<0.001$.

\begin{tabular}{|c|c|c|c|c|c|c|c|c|c|}
\hline \multirow{3}{*}{$\begin{array}{l}\text { MT } \\
\text { Pattern } \\
\text { Line 1, 2 }\end{array}$} & \multicolumn{9}{|c|}{ Line length $(\mathrm{N})=8$} \\
\hline & \multicolumn{3}{|c|}{ Buffer Capacity $(B C)=1$} & \multicolumn{3}{|c|}{$\mathbf{B C}=\mathbf{2}$} & \multicolumn{3}{|l|}{$\mathrm{BC}=4$} \\
\hline & $\mathrm{DI}=2$ & $\mathrm{DI}=5$ & $\mathrm{DI}=12$ & $\mathrm{DI}=\mathbf{2}$ & $\mathrm{DI}=5$ & $\mathrm{DI}=12$ & $\mathrm{DI}=2$ & $\mathrm{DI}=5$ & $D I=12$ \\
\hline,-- 1 & 0.895 & 0.890 & $0.847 * * *$ & 0.933 & 0.921 & $0.860^{* * * *}$ & 0.964 & 0.947 & $0.873^{* * *}$ \\
\hline,-- 1 & 0.892 & 0.885 & $0.843^{* * *}$ & 0.932 & 0.921 & $0.870^{* * * *}$ & 0.957 & 0.943 & $0.874 * * *$ \\
\hline,$-- \Lambda$ & 0.892 & 0.888 & $0.875^{* *}$ & 0.936 & 0.929 & $0.899^{* * * *}$ & 0.965 & 0.956 & $0.917 * * *$ \\
\hline,$-- \mathrm{V}$ & 0.896 & 0.900 & $0.886^{* *}$ & 0.935 & $0.937 *$ & $0.915^{*}$ & $0.961 *$ & 0.961 & $0.935^{* * *}$ \\
\hline $1,--$ & 0.899 & 0.888 & $0.840^{* * *}$ & 0.935 & 0.925 & $0.869^{* * * *}$ & 0.963 & 0.940 & $0.877^{* * *}$ \\
\hline १, \ & 0.897 & 0.887 & $0.837 * * *$ & 0.938 & 0.914 & $0.864 * * *$ & 0.966 & 0.948 & $0.876^{* * *}$ \\
\hline$\backslash, /$ & 0.891 & $0.882 *$ & $0.838^{* * *}$ & 0.929 & 0.920 & $0.859^{* * *}$ & 0.961 & $0.939^{*}$ & $0.873^{* * *}$ \\
\hline$\backslash, \Lambda$ & 0.892 & 0.886 & $0.838^{* * *}$ & 0.935 & 0.924 & $0.860^{* * * *}$ & 0.962 & 0.947 & $0.877^{* * *}$ \\
\hline $1, \mathrm{~V}$ & 0.895 & 0.891 & $0.840^{* * *}$ & 0.937 & $0.919^{*}$ & $0.861^{* * *}$ & 0.963 & $0.934^{* *}$ & $0.884 * * *$ \\
\hline $1,--$ & 0.890 & 0.884 & $0.840^{* * *}$ & 0.933 & 0.923 & $0.898^{* * *}$ & 0.967 & 0.948 & $0.879^{* * *}$ \\
\hline 1,1 & 0.893 & $0.884 *$ & $0.841^{* * *}$ & 0.936 & 0.921 & $0.866^{* * *}$ & 0.960 & $0.939 *$ & $0.876^{* * *}$ \\
\hline 1,1 & 0.885 & $0.873^{* *}$ & $0.828^{* * *}$ & 0.932 & $0.907 * * *$ & $0.858^{* * *}$ & 0.953 & $0.937 * *$ & $0.878^{* * *}$ \\
\hline$I, \Lambda$ & 0.890 & $0.881^{*}$ & $0.837 * * *$ & 0.932 & $0.913 * *$ & $0.871^{* * *}$ & 0.962 & $0.943 *$ & $0.872^{* * * *}$ \\
\hline $1, \mathrm{~V}$ & 0.889 & 0.887 & $0.844 * * *$ & 0.933 & $0.917 *$ & $0.859^{* * *}$ & 0.958 & 0.936 & $0.875^{* * *}$ \\
\hline$\Lambda,--$ & 0.895 & 0.894 & $0.874 * *$ & 0.932 & 0.931 & $0.904 * * *$ & 0.965 & 0.957 & $0.920^{* * * *}$ \\
\hline$\Lambda, 1$ & 0.891 & 0.886 & $0.841^{* * * *}$ & 0.935 & 0.921 & $0.860^{* * * *}$ & 0.966 & 0.941 & $0.871^{* * *}$ \\
\hline$\Lambda, /$ & 0.895 & $0.878^{*}$ & $0.834 * * *$ & 0.930 & $0.917 * *$ & $0.868^{* * *}$ & 0.963 & $0.935^{*}$ & $0.869^{* * *}$ \\
\hline$\Lambda, \Lambda$ & 0.894 & 0.885 & $0.865 * * *$ & 0.934 & 0.929 & $0.904 * * *$ & 0.961 & 0.953 & $0.916^{* * * *}$ \\
\hline$\Lambda, \mathrm{V}$ & 0.891 & 0.891 & $0.871 * *$ & 0.934 & 0.930 & $0.904 * * *$ & 0.965 & 0.954 & $0.924 * * *$ \\
\hline $\mathrm{V},--$ & 0.895 & 0.893 & $0.878^{* *}$ & 0.939 & $0.934 *$ & $0.917^{*}$ & 0.967 & 0.958 & $0.919^{* * *}$ \\
\hline $\mathrm{V}, 1$ & 0.899 & 0.888 & $0.843 * * *$ & 0.934 & $0.917 *$ & $0.860^{* * *}$ & 0.965 & $0.938^{* *}$ & $0.872^{* * * *}$ \\
\hline $\mathrm{V}, 1$ & 0.895 & 0.876 & $0.837 * * *$ & 0.929 & $0.920 *$ & $0.874 * * *$ & 0.959 & 0.940 & $0.882^{* * * *}$ \\
\hline $\mathrm{V}, \Lambda$ & 0.895 & 0.884 & $0.878^{* * *}$ & 0.935 & 0.930 & $0.905^{* * *}$ & 0.964 & 0.952 & $0.924 * * *$ \\
\hline $\mathrm{V}, \mathrm{V}$ & 0.891 & 0.891 & $0.870^{* *}$ & 0.936 & 0.928 & $0.910^{* *}$ & 0.963 & 0.955 & $0.928^{* * *}$ \\
\hline $\begin{array}{c}\text { Balanced } \\
(--,--)\end{array}$ & 0.898 & & & 0.938 & & & 0.966 & & \\
\hline
\end{tabular}

to be unattainable in practice, the best MT unbalanced patterns can be used as alternatives. In contrast, the ascending + ascending MT pattern and any combinations with ascending or descending order, all perform significantly worse than the balanced line.

For ABL, Tukey's results show that the descending + descending $(n, n)$ MT order, as well as any combinations with a descending order outperform the performance of a balanced control. Additionally, in the majority of cases the ascending + ascending $(/, /)$ MT pattern, together with any ascending order combinations perform significantly worse than the control.

Objective 3: Determine the relative effects of line length, BC, MT imbalance pattern, MT degree of imbalance on performance.

The Generalized Linear Model (GLM) was used to determine the relative contributions of the independent variables $(N, \mathrm{BC}$, DI and MTP) on the dependent variables (TR and ABL). Table 7 exhibits the GLM results. Only the highest significance levels (up to 0.037) results are shown, due to space limitations. The link below shows the full data:

https://www.dropbox.com/sh/0o4nwjgg2xroy6i/AAArVioj1EVduySW-mDOgl6Sa?dl=0.

The full data are shown in the two following Excel files:

- FULL-FACTORIAL-?RGINGmMT.xIsx (uploaded on 6/29/2020). 
TABLE 4. ABL results for a merged line with $N=5$ parallel stations, $\mathrm{BC}=1,2$ and 4 units, $\mathrm{DI} \%=2,5$ and 12 , and a balanced line, ${ }^{*} p<0.05,{ }^{* *} p<0.01,{ }^{* * *} p<0.001$.

\begin{tabular}{|c|c|c|c|c|c|c|c|c|c|}
\hline \multirow{3}{*}{$\begin{array}{l}\text { MT } \\
\text { Pattern } \\
\text { Line 1, 2 }\end{array}$} & \multicolumn{9}{|c|}{ Line length $(N)=5$} \\
\hline & \multicolumn{3}{|c|}{ Buffer Capacity $(B C)=1$} & \multicolumn{3}{|l|}{$\mathrm{BC}=\mathbf{2}$} & \multicolumn{3}{|l|}{$\mathrm{BC}=4$} \\
\hline & $\mathrm{DI}=\mathbf{2}$ & $D I=5$ & $\mathrm{DI}=12$ & $D I=2$ & $\mathrm{DI}=5$ & $\mathrm{DI}=12$ & $\mathrm{DI}=2$ & $\mathrm{DI}=5$ & $\mathrm{DI}=12$ \\
\hline,-- 1 & 0.588 & 0.529 ** & $0.504^{* * *}$ & 1.051 & $0.997^{* *}$ & $0.968^{* * *}$ & $2.116^{* *}$ & $2.043 * * *$ & $2.024^{* * *}$ \\
\hline,-- 1 & 0.619 & $0.655^{* *}$ & $0.735^{* * *}$ & $1.273^{* * *}$ & $1.856^{* * * *}$ & $1.543 * * *$ & 2.400 & $2.871^{* * * *}$ & $3.332 * * *$ \\
\hline,$-- \Lambda$ & 0.593 & 0.603 & 0.579 & 1.085 & 1.132 & 1.120 & 2.293 & 2.259 & 2.504 \\
\hline,$-- \mathrm{V}$ & 0.615 & 0.606 & 0.606 & 1.154 & 1.199 & 1.166 & 2.291 & $2.264 * * *$ & $2.616^{*}$ \\
\hline $1,--$ & 0.565 & 0.523 ** & $0.507^{* * *}$ & 1.105 & $1.015^{* *}$ & $1.005 * * *$ & $2.272^{* *}$ & $1.895 * * *$ & 2.012 *** \\
\hline 1,1 & 0.565 & $0.495^{* * *}$ & $0.383^{* * *}$ & $0.991 *$ & $0.896^{* * *}$ & $0.783 * * *$ & $1.844^{* * *}$ & $1.604 * * *$ & $1.551^{* * *}$ \\
\hline ।,/ & 0.593 & 0.609 & 0.589 & 1.184 & 1.168 & $1.264 * *$ & 2.270 & $2.054 * * *$ & 2.284 \\
\hline $1, \Lambda$ & 0.567 & $0.545^{*}$ & $0.494 * * *$ & 1.053 ** & $0.970^{* *}$ & $0.986^{* *}$ & $1.888^{* * *}$ & $1.975^{* * *}$ & $1.999 * * *$ \\
\hline $1, \mathrm{~V}$ & 0.577 & $0.528 * * *$ & $0.485^{* * *}$ & 1.105 & $1.019^{*}$ & $0.927 * * *$ & 2.264 & $1.808^{* * *}$ & $1.942^{* * *}$ \\
\hline $1,--$ & 0.618 & $0.653^{* *}$ & $0.718^{* * *}$ & $1.184^{* *}$ & $1.344^{* * *}$ & $1.594 * * *$ & 2.472 & $2.904 * * *$ & $3.335 * * *$ \\
\hline 1,1 & 0.595 & 0.615 & 0.600 & 1.152 & 1.093 & $1.097^{* *}$ & 2.115 & $2.391 * * *$ & 1.190 \\
\hline I, 1 & 0.638 & $0.690^{* * *}$ & $0.767 * * *$ & $1.255^{* *}$ & $1.387^{* * *}$ & $1.561 * * *$ & 2.562 & $2.905^{* * *}$ & $3.162 * * *$ \\
\hline $1, \Lambda$ & 0.608 & $0.654^{* *}$ & $0.742^{* * *}$ & 1.195 & $1.354 * * *$ & $1.571 * * *$ & $2.645^{*}$ & $2.869^{* * * *}$ & $3.292 * * *$ \\
\hline $1, \mathrm{~V}$ & 0.633 & $0.641 *$ & $0.707^{* * *}$ & 1.222 & $1.267^{* *}$ & $1.531 * * *$ & 2.451 & $2.743^{* * *} *$ & $3.256^{* * *}$ \\
\hline$\Lambda,--$ & 0.603 & 0.583 & 0.591 & 1.155 & 1.155 & 1.172 & 2.418 & 2.314 & 2.513 \\
\hline$\Lambda, \perp$ & 0.580 & $0.545^{*}$ & $0.503^{* * *}$ & $1.090^{* *}$ & $0.955^{* *}$ & $1.002 * *$ & $2.198^{* * *}$ & $1.958 * * *$ & $1.989^{* * *}$ \\
\hline$\Lambda, /$ & 0.602 & $0.663^{* * *}$ & $0.739 * * *$ & 1.226 & $1.336^{* * *}$ & $1.515^{* * *}$ & $2.657 *$ & $2.724 * * *$ & $3.218^{* * *}$ \\
\hline$\Lambda, \Lambda$ & 0.588 & 0.601 & 0.588 & 1.168 & 1.130 & $1.116^{* * *}$ & 2.237 & 2.231 & 2.287 \\
\hline$\Lambda, \mathrm{V}$ & 0.585 & 0.597 & 0.586 & 1.172 & $1.248^{*}$ & 1.182 & 2.332 & $1.929 * * *$ & 2.331 \\
\hline $\mathrm{V},--$ & 0.607 & 0.608 & 0.637 & 1.201 & 1.163 & 1.192 & 2.228 & $2.388 * * *$ & $2.203^{*}$ \\
\hline $\mathrm{V}, 1$ & 0.604 & $0.509 * * *$ & $0.500^{* * *}$ & 1.119 & $1.057^{*}$ & $0.963 * * *$ & 2.052 & $1.911^{* * *}$ & $1.931 * * *$ \\
\hline $\mathrm{V}, 1$ & 0.627 & $0.655^{*}$ & $0.725^{* * *}$ & 1.214 & $1.336^{* *}$ & $1.537 * * *$ & 2.640 & $2.908^{* * *}$ & $3.221 * * *$ \\
\hline $\mathrm{V}, \Lambda$ & 0.600 & 0.592 & 0.598 & 1.156 & $1.113^{*}$ & 1.242 & 2.256 & $2.365^{* * *}$ & 2.565 \\
\hline $\mathrm{V}, \mathrm{V}$ & 0.606 & 0.591 & 0.609 & 1.168 & 1.197 & $1.219 *$ & 2.235 & 2.330 & $2.082 * * *$ \\
\hline $\begin{array}{c}\text { Balanced } \\
(--,--)\end{array}$ & 0.594 & & & 1.120 & & & 2.382 & & \\
\hline
\end{tabular}

- Merging MT- data.xIsx (uploaded on 6/29/2020).

As seen in Table 7, for both TR and ABL, all the main effects (i.e. $N$, BC, DI and MTP) and many of the 1st to 3rd degree interactions are very highly significant at the 0.000 level.

The most influential effect on TR turned out to be DI, followed respectively by BC and MTP.

Regarding ABL, the most significantly important factor affecting performance is BC, then MTP, followed by the five different interactions combining MTP with other variables.

\section{Summary OF MAIN RESUlts}

Several general conclusions can be drawn from this study. When TR is considered, a balanced + balanced line yields the best performance. This concurs with the findings of McNamara et al. [45] for single serial lines. Despite that alignment, other previous literature results are dissimilar. For example, results here differ from Baker et al.'s [5] findings on short three-station merging systems with two parallel feeders and an assembly 
TABLE 5. ABL results for a merged line with $N=8$ parallel stations, $\mathrm{BC}=1,2$ and 4 units, $\mathrm{DI} \%=2,5$ and 12 , and a balanced line, ${ }^{*} p<0.05,{ }^{* *} p<0.01,{ }^{* * *} p<0.001$.

\begin{tabular}{|c|c|c|c|c|c|c|c|c|c|}
\hline \multirow{3}{*}{$\begin{array}{l}\text { MT } \\
\text { Pattern } \\
\text { Line 1, 2 }\end{array}$} & \multicolumn{9}{|c|}{ Line length $(\mathrm{N})=8$} \\
\hline & \multicolumn{3}{|c|}{ Buffer Capacity $(B C)=1$} & \multicolumn{3}{|l|}{$\mathrm{BC}=2$} & \multicolumn{3}{|l|}{$\mathrm{BC}=4$} \\
\hline & $\mathrm{DI}=\mathbf{2}$ & $\mathrm{DI}=5$ & $\mathrm{DI}=12$ & $\mathrm{DI}=\mathbf{2}$ & $\mathrm{DI}=5$ & $\mathrm{DI}=12$ & $\mathrm{DI}=\mathbf{2}$ & $\mathrm{DI}=5$ & $\mathrm{DI}=12$ \\
\hline,-- 1 & 0.589 & $0.529 * * *$ & $0.511^{* * *}$ & 1.100 & $0.991^{* * *}$ & $1.035^{*}$ & 2.379 & $2.009 * * *$ & $2.061 * *$ \\
\hline,-- 1 & 0.631 & $0.664 * * *$ & $0.764 * * *$ & $1.271^{* * *}$ & $1.371^{* * *}$ & $1.588^{* * *}$ & $2.640^{* * *}$ & $2.948^{* * * *}$ & $3.436^{* * * *}$ \\
\hline,$-- \Lambda$ & 0.620 & 0.624 & 0.607 & $1.219 *$ & 1.166 & $1.242^{* * *}$ & 2.261 & 2.386 & $2.655^{* * * *}$ \\
\hline,$-- \mathrm{V}$ & 0.578 & 0.586 & $0.600^{* *}$ & 1.187 & 1.156 & 1.295 & 2.456 & $2.104 * * *$ & $2.512^{* * *}$ \\
\hline $1,--$ & 0.570 & $0.516^{* * *}$ & $0.520 * * *$ & 0.990 & $0.963^{* * *}$ & $1.023 *$ & 2.223 & $1.996 * * *$ & $2.085^{* *}$ \\
\hline 1,1 & $0.551^{* *}$ & $0.451^{* * *}$ & $0.380^{* * *}$ & 1.119 & $0.964^{* * *}$ & $0.800^{* * *}$ & $1.948^{* * *}$ & $1.432 * * *$ & $1.105^{* * *}$ \\
\hline$\backslash, /$ & 0.616 & 0.617 & $0.642 *$ & 1.163 & 1.160 & $1.031^{*}$ & 2.229 & $2.560^{* * *}$ & $2.495^{* * *}$ \\
\hline $1, \Lambda$ & $0.551^{*}$ & $0.541^{* * *}$ & $0.495^{* * *}$ & 1.095 & $0.930^{* * *}$ & $0.977 * * *$ & $2.008^{* * *}$ & $1.828^{* * *}$ & $1.985^{* * *}$ \\
\hline$\backslash, \mathrm{V}$ & 0.567 & $0.524 * * *$ & 0.519 *** & 1.055 & $1.005^{* *}$ & 1.034* & 2.066* & $1.985^{* * *}$ & $1.981^{* * *}$ \\
\hline 1,-- & 0.628 & $0.680^{* * *}$ & $0.785^{* * *}$ & $1.232 * * *$ & $1.352 * * *$ & $1.083^{* * *}$ & $2.334 * * *$ & $2.876^{* * *}$ & $3.402^{* * *}$ \\
\hline 1,1 & 0.584 & 0.588 & $0.590^{*}$ & 1.139 & 1.178 & 1.121* & 2.342 & $2.557 * * *$ & $2.203^{* * *}$ \\
\hline 1,1 & $0.645^{*}$ & $0.708^{* * *}$ & $0.782 * * *$ & $1.238^{* *}$ & $1.413 * * *$ & $1.597 * * *$ & $2.778^{* * *}$ & $3.021^{* * *}$ & $3.269^{* * *}$ \\
\hline $1, \Lambda$ & 0.634 & 0.639 & $0.755^{* * *}$ & $1.246^{* *}$ & $1.347 * * *$ & $1.547 * * *$ & $2.542^{* * *}$ & $2.972 * * *$ & $3.379^{* * *}$ \\
\hline $1, \mathrm{~V}$ & 0.614 & 0.623 & $0.753^{* * *}$ & 1.196 & $1.387 * * *$ & $1.609^{* * *}$ & $2.543 * * *$ & $3.035^{* * *}$ & $3.365^{* * *}$ \\
\hline$\Lambda,--$ & 0.591 & 0.592 & 0.604 & $1.194^{*}$ & 1.138 & $1.255^{* * *}$ & 2.333 & 2.280 & $2.617^{* * *}$ \\
\hline$\Lambda, \backslash$ & $0.572 *$ & $0.525^{\text {*** }}$ & $0.470^{* * * *}$ & 1.014 & $0.964^{* * *}$ & $1.002^{* * *}$ & $2.075 \div * *$ & $1.971 * * *$ & $1.99 * * *$ \\
\hline$\Lambda, /$ & 0.603 & 0.647 & $0.754 * * *$ & $1.293 * *$ & $1.335 * * *$ & $1.547 * * *$ & $2.508^{* * *}$ & $3.002 * * *$ & $3.398^{* * *}$ \\
\hline$\Lambda, \Lambda$ & 0.598 & 0.583 & 0.576 & $1.236^{* *}$ & 1.071 & 1.130 & 2.149 & 2.125 & $2.436^{* *}$ \\
\hline$\Lambda, \mathrm{V}$ & 0.604 & 0.589 & 0.596 & 1.184 & 1.163 & $1.246^{* * *}$ & 2.402 & 2.392 & 2.140 \\
\hline $\mathrm{V},--$ & 0.589 & 0.624 & $0.656^{* *}$ & 1.126 & 1.150 & 1.120 & 2.284 & $2.578^{* * *}$ & $2.791^{* * * *}$ \\
\hline $\mathrm{V}, \backslash$ & 0.618 & $0.552 * * *$ & $0.493 * * *$ & 1.109 & $1.013^{* *}$ & $1.021 *$ & $1.964 *$ & $1.986 * * *$ & $2.033^{* * *}$ \\
\hline $\mathrm{V}, 1$ & 0.620 & 0.681 & $0.756^{* * * *}$ & 1.315 & $1.390^{* * * *}$ & $1.534 * * *$ & $2.613 * * *$ & $2.946^{* * * *}$ & $3.282 * * *$ \\
\hline $\mathrm{V}, \Lambda$ & 0.603 & 0.615 & 0.589 & 1.145 & 1.177 & $1.207 * * *$ & 2.176 & 2.480 & 2.321 \\
\hline $\mathrm{V}, \mathrm{V}$ & 0.605 & 0.643 & $0.667 * * *$ & $1.216^{*}$ & $1.216^{*}$ & 1.177 & 2.221 & $2.430 *$ & $2.457^{* *}$ \\
\hline $\begin{array}{c}\text { Balanced } \\
(--,-)\end{array}$ & \multicolumn{3}{|l|}{0.604} & \multicolumn{3}{|l|}{1.123} & \multicolumn{3}{|l|}{2.254} \\
\hline
\end{tabular}

TABLE 6. Homogeneous subgroups for the performance ranking of different MT imbalance patterns.

\begin{tabular}{|l|l|l|l|}
\hline $\begin{array}{l}\text { Performance } \\
\text { Indicator }\end{array}$ & \multicolumn{1}{|c|}{$\begin{array}{c}\text { Subgroup 1 } \\
\text { (Best Patterns) }\end{array}$} & \multicolumn{1}{c|}{$\begin{array}{c}\text { Subgroup 2 } \\
\text { (Medium Patterns) }\end{array}$} & \multicolumn{1}{c|}{$\begin{array}{c}\text { Subgroup 3 } \\
\text { (Worst Patterns) }\end{array}$} \\
\hline TR & Best = balanced line & $\begin{array}{l}\text { Balanced line + Bowl } \\
\text { Balanced + inverted bowl } \\
\text { Bowl + Bowl } \\
\text { Inverted bowl + Inverted bowl }\end{array}$ & $\begin{array}{l}\text { Worst = ascending+ ascending } \\
\text { Combinations with ascending } \\
\text { or descending order }\end{array}$ \\
\hline ABL & $\begin{array}{l}\text { Best = descending + } \\
\text { descending } \\
\text { Combinations with } \\
\text { descending order }\end{array}$ & $\begin{array}{l}\text { Combinations with bowl and } \\
\text { inverted bowl }\end{array}$ & $\begin{array}{l}\text { Worst = ascending +ascending } \\
\text { Combinations with ascending } \\
\text { order }\end{array}$ \\
\hline
\end{tabular}


TABLE 7. GLM results for TR and ABL: significant at ${ }^{*} p<0.05,{ }^{* *} p<0.01,{ }^{* * *} p<0.001$.

\begin{tabular}{|c|c|c|c|c|c|}
\hline \multirow{3}{*}{\begin{tabular}{|l|} 
Performance \\
Deviance \\
Source (Factor)
\end{tabular}} & \multicolumn{2}{|c|}{ Throughput (TR) } & \multicolumn{3}{|c|}{ Average Buffer Level (ABL) } \\
\hline & \multicolumn{2}{|l|}{13.735} & & \multicolumn{2}{|l|}{181.390} \\
\hline & $\begin{array}{l}\text { Wald Chi- } \\
\text { Square }\end{array}$ & $\begin{array}{l}\text { Significance } \\
\text { Level }\end{array}$ & Source (Factor) & $\begin{array}{l}\text { Wald Chi- } \\
\text { Square }\end{array}$ & $\begin{array}{l}\text { Significance } \\
\text { Level }\end{array}$ \\
\hline DI & $5,513.860^{* * *}$ & 0.000 & BC & $67,415.608^{* * *}$ & 0.000 \\
\hline $\mathbf{B C}$ & $5,010.766^{* * *}$ & 0.000 & MTP & $5,074.650^{* * *}$ & 0.000 \\
\hline МTP & $816.920^{* * *}$ & 0.000 & BC*MTP & $2,449.650^{* * *}$ & 0.000 \\
\hline DI*MTP & $719.942^{* * *}$ & 0.000 & DI*MTP & $972.227^{* * *}$ & 0.000 \\
\hline BC*DI & $274.366^{* * *}$ & 0.000 & BC*DI*MTP & $462.705^{* * *}$ & 0.000 \\
\hline $\mathbf{N}$ & $45.494^{* * *}$ & 0.000 & $\mathrm{~N} * \mathrm{BC} * \mathrm{DI} * \mathrm{MTF}$ & $\mathbf{P} 187.741^{* * *}$ & 0.000 \\
\hline $\mathbf{N} * \mathbf{B C}$ & $17.994^{* * *}$ & 0.000 & $\mathbf{N} * \mathbf{B C} * \mathbf{M T P}$ & $137.775^{* * *}$ & 0.000 \\
\hline $\mathbf{N} * \mathbf{D I}$ & $10.276^{* * *}$ & 0.006 & DI & $132.970^{* * * *}$ & 0.000 \\
\hline \multirow[t]{5}{*}{ BC*MTP } & $40.186^{* * *}$ & 0.037 & $\mathbf{N} * \mathrm{DI} * \mathrm{MTP}$ & $119.167^{* * *}$ & 0.000 \\
\hline & & & BC*DI & $100.913^{* * *}$ & 0.000 \\
\hline & & & $\mathbf{N} * \mathbf{M T P}$ & $50.808^{* * *}$ & 0.000 \\
\hline & & & $\mathbf{N}$ & $32.796^{* * *}$ & 0.000 \\
\hline & & & $\mathbf{N} * \mathbf{B C}$ & $19.891^{* * *}$ & 0.000 \\
\hline
\end{tabular}

station, which found that an unbalanced line was optimal. It also conflicts with Bhatnagar and Chandra [6], who stated that decreasing operation times can lead to great improvements in TR, as well as with Magazine and Stecke [43], who indicated that when the feeder stations are faster than the merge station, best results are likely achieved.

Although results indicated that the balanced + balanced line arrangement was superior in most cases, it also showed that it did not significantly differ in TR from four reasonably good unbalanced MT patterns (balanced line + bowl, balanced + inverted bowl, bowl + bowl, and inverted bowl + inverted bowl). This lends support to the 3-station merging line results of Baker et al. [5], as well as to the longer 5- and 8-station merging lines considered in our research.

Also observed was a bowl-shaped configuration (bowl + bowl) provided good MT pattern results. This suggests that the bowl phenomenon $[25,55]$ remains valid for merging assembly lines. Specific to apparel manufacturing, this suggests that there are several alternatives to improve performance even when faced with the line variability and complexity common to the industry.

For ABL, the best MT pattern was found to be a descending + descending MT order. This is in line with the conclusion of Kadipasaoglu et al. [32] that for single serial lines, the constraint station should be positioned at the beginning of the line to minimise WIP. It also complements Shaaban and McNamara [55] work on a single reliable single line performance. In addition, it was observed that the descending patterns resulted in substantial performance improvements over the control pattern, while most ascending patterns resulted in substandard performance.

Study results also suggest that the best TR performance is most influenced first by degree of MT imbalance, then buffer capacity (BC) and MTP, whereas best ABL performance is most influenced first by BC and then MTP.

In addition, it can be seen from Tables 2 and 3 that TR goes down (deteriorates) as $N$, BC and DI are increased. On the other hand, we can discern from Tables 4 and 5 that ABL will increase (deteriorate) as $N$ and $\mathrm{BC}$ increases. 
Moreover, for the best and good MT configurations in terms of ABL, consistent, mostly highly significant improvements over the balanced line are obtained for all the $N, \mathrm{BC}$, and DI values explored.

Furthermore, the highest \% ABL improvement over an equivalent balanced merging line is $50.98 \%$ (very highly significant), which was achieved for the pattern descending + descending at relatively high levels of $N$, $\mathrm{BC}$ and $\mathrm{DI}(N=8, \mathrm{BC}=4$ and $\mathrm{DI}=12 \%)$, with an $\mathrm{ABL}$ of 1.105 in comparison with 2.254 for the balanced merging line.

\section{Discussion AND FURTHER RESEARCH}

The main aim of this research was to gauge the impact of unbalancing mean operation times on a merging production line's efficiency.

This study indicates that some MT unbalanced configurations can achieve a statistically equivalent TR performance to that of a balanced merging line. In addition, statistically highly significant ABL performance is attainable in many MT unbalanced configurations (around $51 \%$ for the best case). Such saving levels could justify the purposeful unbalancing of merging assembly lines, as a reduction in ABL entails no further capital or resource expenditures, but only appropriately allocating workers to the same stations.

Despite the valuable enhancements suggested via this research, this study's results are not a panacea. In a high-demand, fully utilized labour industry (e.g. the IT, or certain consumer goods industries), throughput may be prioritized. In the apparel industry, particularly in less developed economies with high demand and poorly utilized workers, the best or other favorable MT unbalanced configurations (such as the balanced + bowl pattern) might be prioritized and selected to achieve the largest possible throughput improvement.

In a just-in-time, lean-buffering industry (e.g. the electronics or automotive industries), ABL would be prioritized. In this situation, the best MT unbalanced pattern (descending + descending), or other advantageous configurations (such as bowl + inverted bowl) would be the most suitable.

As with all research of this nature, these results have limited generalizability. Simulation methodology is a valuable and useful analytical tool that can represent realistic situations more accurately than many mathematical models, yet it still includes assumptions that simplify processes and removes some practical applications.

Also, results here are based on performing simulation runs on only a limited number of unbalanced MT configurations among an almost infinite number of alternative MT patterns. In addition, if the line is unbalanced in the wrong manner, inferior performance could result despite the potential advantages of an unbalanced line.

Future research may study merging lines with two or three simultaneous sources of imbalance (e.g. joint MT and CV imbalance), or unbalanced disassembly lines.

\section{REFERENCES}

[1] J. Abu Qudeiri, H. Yamamoto, R. Ramli and A. Jamali, Genetic algorithm for buffer size and work station capacity in serial-parallel production lines. Artif. Life Rob. 12 (2008) 102-106.

[2] S.K. Bahadir, Assembly line balancing in garment production by simulation, edited by W. Grzechca. In: Assembly Line Theory and Practice, IntechOpen (2011).

[3] K.R. Baker and S.G. Powell, A predictive model for the throughput of simple assembly systems. Eur. J. Oper. Res. 81 (1995) $336-345$.

[4] K.R. Baker, S.G. Powell and D.F. Pyke, Buffered and un-buffered assembly systems with variable processing times. J. Manuf. Oper. Manage. 3 (1990) 200-223.

[5] K.R. Baker, S.G. Powell and D.F. Pyke, Optimal allocation of work in assembly systems. Manage. Sci. 39 (1993) $101-106$.

[6] R. Bhatnagar and P. Chandra, Variability in assembly and competing systems: effect on performance and recovery. IIE Trans. 26 (1994) 18-31.

[7] J.H. Blackstone Jr and J.F. Cox III, Designing unbalanced lines-understanding protective capacity and protective inventory. Prod. Plan. Control 13 (2002) 416-423.

[8] C.C. Chan, C.L. Hui, K.W. Yeung and S.F. Ng, Handling the assembly line balancing problem in the clothing industry using a genetic algorithm. Int. J. Clothing Sci. Technol. 10 (1998) 21-37.

[9] T.S. Cocks and S.C. Harlock, Computer-aided simulation of production in the sewing room of a clothing factory. J. Text. Inst. 80 (1989) 455-463.

[10] R. Conway, W. Maxwell, J.O. McClain and L.J. Thomas, The role of work-in-process inventory in serial production lines. Oper. Res. 36 (1988) 229-241. 
[11] B. Das, J.M. Sanchez-Rivas, A. Gacia-Diaz and C.A.A. MacDonald, Computer simulation approach to evaluating assembly line balancing with variable operation times. J. Manuf. Technol. Manage. 2 (2010) 872-887.

[12] W.J. Doll and M.A. Vonderembse, The evolution of manufacturing systems: towards the post-industrial enterprise. Omega 19 (1991) 401-411.

[13] T. El-Rayah, The efficiency of balanced and unbalanced production lines. Int. J. Prod. Res. 17 (1997) 61-75.

[14] S.H. Eryuruk, Clothing assembly line design using simulation and heuristic line balancing techniques. J. Textile Apparel/Tekstil ve Konfeksiyon 22 (2012) 360-368.

[15] M. Fleischmann, P. Beullens, J.M. Bloemhof-Ruwaard and L.N. Wassenhove, The impact of product recovery on logistics network design. Prod. Oper. Manage. 10 (2001) 156-173.

[16] G. Fozzard, J. Spragg and D. Tyler, Simulation of flow lines in clothing manufacture. Part 1: model construction. Int. J. Clothing Sci. Technol. 8 (1996) 17-27.

[17] K. Futamura, The multiple server effect: optimal allocation of servers to stations with different service-time distributions in tandem queueing networks. Ann. Oper. Res. 93 (2000) 71-90.

[18] H. Gökçen, K. Ağpak and R. Benzera, Balancing of parallel assembly lines. Int. J. Prod. Econ. 103 (2006) 600-609.

[19] A. Grosfeld-Nir and T. Ben-Zvi, Multistage production systems with random yields and rigid demand. Int. J. Manuf. Technol. Manage. 20 (2010) 286-299.

[20] V.D.R. Guide and L.N. Wassenhove, Managing product returns for remanufacturing. Prod. Oper. Manage. 10 (2001) $142-155$.

[21] M. Gungor and S. Agac, Resource-constrained mixed model assembly line balancing in an apparel company. J. Textile Apparel/Tekstil ve Konfeksiyon 24 (2014) 405-412.

[22] M. Güner and C. Ünal, Line balancing in the apparel industry using simulation techniques. Fibres Textiles Eastern Europe 16 (2008) $75-78$.

[23] C. Harrell, B.K. Ghosh, R.O. Bowden, Simulation Using ProModel. McGraw Hill, New York, NY (2004).

[24] M. Hillier, Designing unpaced production lines to optimize throughput and work-in-process inventory. IEEE Trans. 45 (2013) $516-527$.

[25] F.S. Hillier and R.W. Boling, The effect of some design factors on the efficiency of production lines with variable element times. J. Ind. Eng. 17 (1966) 651-658.

[26] S.J.T. Hsieh, Hybrid analytic and simulation models for assembly line design and production planning. Simul. Modell. Pract. Theory 10 (2002) 87-108.

[27] S. Hudson, T. McNamara and S. Shaaban, Unbalanced lines: where are we now? Int. J. Prod. Res. 53 (2015) $1895-1911$.

[28] S.T. Hutchinson, J.R. Villalobos and M.G. Beruvides, Effects of high labour turnover in a serial assembly environment. Int. J. Prod. Res. 35 (1997) 3201-3223.

[29] K.C. Jeong and Y.-D. Kim, Technical note: an approximation method for performance analysis of assembly/disassembly systems with parallel-machine stations. IEEE Trans. 31 (1999) 391-394.

[30] K.C. Jeong and Y.-D. Kim, Heuristics for selecting machines and determining buffer capacities in assembly systems. Comput. Ind. Eng. 38 (2000) 341-360.

[31] Z. Jia, L. Zhang, J. Arinez and G. Xiao, Performance analysis of assembly systems with Bernoulli machines and finite buffers during transients. IEEE Trans. Autom. Sci. Eng. 13 (2016) 1018-1032.

[32] S.N. Kadipasaoglu, W. Xiang, S.F. Hurley and B.M. Khumawala, A study on the effect of the extent and location of protective capacity in flow systems. Int. J. Prod. Econ. 63 (2000) 217-228.

[33] F. Kalaoğlu and C. Saricam, Analysis of modular manufacturing system in clothing industry by using simulation. Fibres Text. Eastern Eur. 15-3 (2007) 93-96.

[34] M. Kayar and M. Akalin, Comparing the effects of automat use on assembly line performance in the apparel industry by using a simulation method. Fibres Text. Eastern Eur. 23-5 (2015) 114-123.

[35] M. Kayar and M. Akalin, Comparing heuristic and simulation methods applied to the apparel assembly line balancing problem. Fibres Text. Eastern Eur. 24 (2016) 131-137.

[36] C.T. Kuo, J.T. Lim, S.M. Meerkov and E. Park, Improvability theory for assembly Systems: two component, one assembly machine case. Math. Prob. Eng. 3 (1996) 95-171.

[37] A.M. Law, Simulation Modeling and Analysis. Irwin/McGraw-Hill, Illinois (2007).

[38] J.W.K. Leung and K.K. Lai, Analysis of strategies for installing parallel stations in assembly systems. Ind. Eng. Manage. Syst. 4 (2005) 117-122.

[39] J.E. Li, D. Blumenfeld, N.M. Huang and J. Alden, Throughput analysis of production systems: recent advances and future topics. Int. J. Prod. Res. 47 (2009) 3823-3851.

[40] X.G. Liu and J.A. Buzacott, Approximate models of assembly systems with finite inventory banks. Eur. J. Oper. Res. 45 (1990) $143-54$.

[41] C.E. Lopez, Unbalanced workload allocation in large assembly lines. MS dissertation, Department of Industrial and Systems Engineering, Rochester Institute of Technology (2014).

[42] K.E. Maani and G.L. Hogg, A stochastic network simulation model for production line systems. Int. J. Prod. Res. 18 (1980) 723-739.

[43] M.J. Magazine and K.E. Stecke, Throughput for production lines with serial work stations and parallel service facilities. Perform. Eval. 25 (1996) 211-232.

[44] T. McNamara, S. Shaaban and S. Hudson, Simulation of unbalanced buffer allocation in unreliable unpaced production lines. Int. J. Prod. Res. 51 (2013) 1922-1936. 
[45] T. McNamara, S. Shaaban and S. Hudson, Mean time imbalance effects on unreliable unpaced serial flow line. J. Manuf. Syst. 33 (2014) 357-365.

[46] L.E. Moberly and F.P. Wyman, An application of simulation to the comparison of assembly line configurations. Decis. Sci. 4 (1973) 505-516.

[47] A. Patchong and D. Willaeys, Modeling and analysis of an unreliable flow line composed of parallel-machine stages. IIE Trans. 33 (2001) 559-568.

[48] S.G. Powell, Buffer allocation in unbalanced three-station serial lines. Int. J. Prod. Res. 32 (1994) $2201-2217$.

[49] S.G. Powell and D.F.I. Pyke, Buffering unbalanced assembly systems. IIE Trans. 30 (1998) 55-65.

[50] M.M. Rahman, F. Nur and S. Talapatra, An integrated framework of applying line balancing in apparel manufacturing organization: a case study. J. Mech. Eng. 44 (2015) 117-123.

[51] I. Rekhi, S. Chand and H. Moskowitz, A note on optimal allocation of work in stochastic assembly systems. Eur. J. Oper. Res. 137 (2002) 387-393.

[52] R. Romero-Silva and S. Shaaban, Influence of unbalanced operation time means and uneven buffer allocation on unreliable merging assembly line efficiency. Int. J. Prod. Res. 57 (2019) 1645-1666.

[53] I. Sabuncuoglu, E. Erel and A.G. Kok, Analysis of assembly systems for interdeparture time variability and throughput. IIE Trans. 34 (2002) 23-40.

[54] I. Sabuncuoglu, E. Erel and Y. Gocgun, Analysis of serial production lines: characterisation study and a new heuristic procedure for optimal buffer allocation. Int. J. Prod. Res. 44 (2006) 2499-2523.

[55] S. Shaaban and T. McNamara, Improving the efficiency of unpaced production lines by unbalancing service time means. Int. J. Oper. Res. 4 (2009) 346-361.

[56] S. Shaaban, T. McNamara and V. Dmitriev, Asymmetrical buffer allocation in unpaced merging assembly lines. Comput. Ind. Eng. 109 (2017) 211-220.

[57] N. Slack, Work time distributions in production system modelling. Research paper, Oxford Centre for Management Studies (1982).

[58] B.A. Tan, Three-station merge system with unreliable stations and a shared buffer. Math. Comput. Modell. 33 (2001) 10111026.

[59] F. Thiesse and E. Fleisch, On the value of location information to lot scheduling in complex manufacturing processes. Int. J. Prod. Econ. 112 (2008) 532-547.

[60] L. Tiacci, Simultaneous balancing and buffer allocation for the design of mixed-model assembly lines with parallel workstations and stochastic task times. Int. J. Prod. Econ. 162 (2015) 201-215.

[61] M.A. Vonderembse and G.P. White, Core Concepts of Operations Management. Wiley-Higher Education, Hoboken, NJ (2004).

[62] World Trade Organization (2014) International Trade Statistics 2014. Available at: https://www.wto.org/english/res_e/ statis_e/its2014_e/its14_highlights2_e.pdf (Accessed: July 29, 2016).

[63] M.F. Yegul, F.S. Erenay, S. Striepe and M. Yavuz, Improving configuration of complex production lines via simulation-based optimization. Comput. Ind. Eng. 109 (2017) 295-312.

[64] J. Zielinski and M. Czacherska, Optimisation of the work of a sewing team by using computer simulation. Fibres Text. Eastern Eur. 12 (2004) 78-82. 